\title{
Adapting the Framework to Studio Art disciplines
}

$\mathbf{B}_{\mathrm{r}}^{\mathrm{c}}$ ecause of its emphasis on knowledge practices and dispositions over prescriptive skills, the ACRL "Framework for Information Literacy for Higher Education" resonates with subject specialist librarians who may have found it difficult to apply the ACRL "Information Literacy Competency Standards for Higher Education" to their particular programs. For example, the research and corresponding library instruction that supports Studio Art coursework and artistic practice often looks very different from the methods used to conduct scholarship in other disciplines.

Four art librarians, inspired by the Framework, collaborated to develop the mnemonic device CREATE (Conversation, Revision, Exploration, Authority, Thoughtful, Experiential), drawing parallels between the research process and the creative process. CREATE adapts Framework concepts to Studio Art disciplines, making information literacy more relevant to students in these programs.

\section{The collaboration}

Although the authors represent a range of institutional types (a midsized and a large public university with programs in art and design, a mid-sized private Art and Design school, and a small art college recently acquired by a large private research university) and geographic locations, we all share a common job function: providing research assistance and information literacy education to students in studio art disciplines.
Amanda Meeks, teaching, learning, and research services librarian at Northern Arizona University, developed CREATE as a learning tool for students by identifying information literacy concepts applicable to Studio Art research practices. She then reached out to colleagues whom she thought might be interested in testing this tool at their own institutions. Each librarian incorporated CREATE into their individual teaching practices and shared their experiences through regular check-in conversations. Collaboratively, the group further elaborated the theoretical underpinnings of CREATE by writing descriptions that connect research practices to the creative process.

\section{The tool}

CREATE can be used to introduce, reinforce, and enhance information literacy for learners in Art and Design disciplines. In keeping with the ethos of the Framework, CREATE is meant to be flexible in its application. It is not prescriptive and does not provide a how-to guide for working with creative stu-

\footnotetext{
Amanda Meeks is teaching, learning and research services librarian at Northern Arizona University, email: amanda.meeks@nau.edu, Larissa Garcia is information literacy librarian and art subject specialist at Northern Illinois University, email: larissagarcia@niu. edu, Ashley Peterson is research and instruction librarian at the School of the Museum of Fine Arts at Tufts University, email: a.peterson@tufts.edu, Alyssa Vincent is information services librarian at Northeastern Illinois University, email: avincent17@gmail.com
}

C 2017 Amanda Meeks, Larissa Garcia, Ashley Peterson, and Alyssa Vincent 
dents. Instead, its concepts (and the Framework concepts) contextualize information literacy within the discipline.

The elements of CREATE are:

Conversation. Making art is an expression of new insights and discoveries occurring over time as a result of varied perspectives and interpretations. By providing attribution to relevant previous research, you not only participate in the conversation, but you also help move it forward. Your work is a way for you to enter this ongoing conversation and contribute to the discourse or build on the work of others. It is important to recognize the contributions of other thinkers in order to contextualize your work and place it in relation to the larger context of art history, ideology, and social communities.

Revision. Artists create, go through critique, research, and revise their work in order to develop images and formats that most accurately represent their vision. Similarly, information creation is a process that requires mental flexibility to research, create, revise, and disseminate information. Just as the development of your work is an iterative process, so too is the research process, as you will ask increasingly complex or new questions that lead you to different lines of inquiry.

Exploration. Creative research is a nonlinear process in which one identifies a need and seeks the best resource to meet that need. Like inspiration, quality information can often be found where it's least expected, through serendipitous means and through a very intentional, strategic approach. It's important for one to cultivate mental flexibility in their learning process, as well as their art practice, and observe how one informs the other. Considering a range of resources to begin any creative endeavor furthers the process of exploring, interpreting, and analyzing all types of relevant media, which in turn will guide you through this iterative phase of learning.

Authority. Your work, be it visual or printed, formal or informal, reflects your expertise and credibility. While you are the authority on your own creative work, it is shaped by the context in which work is presented or used. Additionally, there are many different types of authority to acknowledge and grapple with, including professional experience and subject expertise. When engaging with others' work, for inspiration or as a resource, it is important to critically consider and evaluate the authority of those creators and their contributions to your discipline.

Thoughtful. Continually asking increasingly complex or new questions can inspire future lines of inquiry for creative work. To further enrich your work, strive to consider every possible solution and angle to approaching a creative project. It is important to brainstorm ideas that are both possible and impossible, as well as challenge any of your own or others' assumptions or biases that may arise in this process. Self-reflection and the critical evaluation of ideas will help you synthesize what you have learned to deepen your understanding, interpret meaning in your work and others', and help you create informed artwork and design solutions.

Experiential. Whether processing past experiences or exploring new avenues of inquiry, the work is an expression of one's own observations and understandings. While a "traditional" research process can lead to inspiration and focus, all of the materials experimentation, sketches, false starts, and iterations are a kind of tactile/haptic research and are an important part of the creation of a piece. These experiences are affected by the cognitive, affective, and social dimensions of the artist, and it is their synthesis that produces the work.

\section{The applications}

Ashley Peterson, research and instruction librarian at the School of the Museum of Fine Arts at Tufts University, uses CREATE during the planning stages of her information literacy teaching. Whether she's creating lesson plans for one-shot sessions or strategizing a more embedded role within a course, the device helps her apply the Framework to Studio Art education and make it relevant for her students.

For example, she works closely with the senior thesis program at her institution, guiding and supporting student artists throughout an entire academic year as they develop 


\section{New Digital Resources from the OECD}

Building upon the success of our iLibrary platform, we at OECD have spent the past few years developing "iLibraries" for other international organisations, using the same trusted technology and incorporating the same easy-to-use features and functionality for users.

- The sites are free to browse and read.

- Full capabilities including download, save, copy, cite and measure with subscription.

- Content and data in one easy to use platform.

- Full access to the resources of these highly respected organisations will enable you and your colleagues to complete research tasks even more quickly and effectively.

If you are interested in learning more about any of these resources please contact Iain Williamson at iain.williamson@oecd.org or call 202-822-3870.

For general iLibrary information please visit www.oecd-ilibrary.org 


\section{OECDiLibrary}

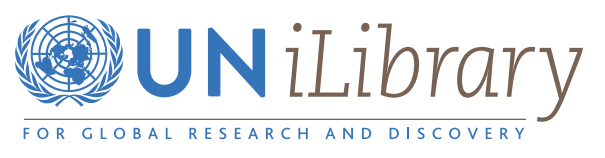

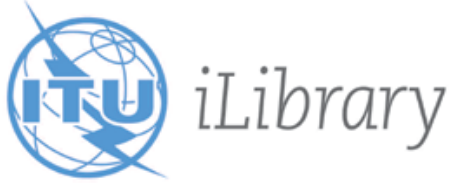

ww" The Commonwealth iLibrary

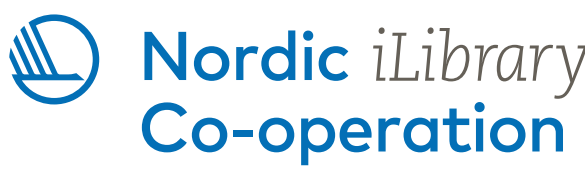


their thesis projects. To frame the role of research in the creative process as illustrated by CREATE, she paraphrases for the class a 2006 quote from James Elmborg: "Information can [be] redefined as the raw material students use to solve [problems] and to create their own understandings and identities, rather than as something 'out there' to be accessed efficiently."1 Because Art students are already familiar with the physical raw materials that result in a work of art (cameras, canvas, metal, fabric, bodies, etc.), Peterson can contextualize research and information as another essential part of creative practice.

Alyssa Vincent, information services librarian at Northeastern Illinois University, also uses CREATE in her planning for library sessions. Rather than sticking to the same lesson plans from past semesters, the tool is her inspiration for rethinking the library instruction that would most benefit students in Art History classes. Vincent also uses it as an entry point to talk with Studio Art faculty about the value of research in studio practice.

Meeks uses CREATE in conjunction with backwards instructional design theory when planning instruction sessions for her Art and Design students. This process allows for the development of new knowledge practices, learning objectives, and essential questions to ask students that encourage self-reflection and a deeper understanding of the relationship between the creative and research practices.

Each session or meeting is an opportunity to recognize students' unique challenges and different approaches to research and creativity. For example, in a first-year English course for Art majors, Meeks asked students to define for themselves what each element of CREATE means and then facilitated a discussion about the context in which these concepts might be applied. As a result, students were able to view their writing process as an extension of their art-making instead of looking at the assignment as devoid of all creativity. Considering each research assignment as an outlet for creativity and curiosity empowers even first-year students in any discipline.

In a one-shot session with an upper-level
Land and Environmental Art class at Northern Arizona University, Meeks focused on the concept Thoughtful, developing essential questions for each CREATE concept that students could reflect on individually. Through this exercise, students shared key insights into their creative research practices, with some students noting that they had "never thought about their process this way before." At the final show for the class, not only did the instructor highlight student-artist engagement with CREATE concepts, but students were more articulate about the research component that went into their work.

At Northern Illinois University, Information Literacy Librarian and Art Subject Specialist Larissa Garcia uses the tool to contextualize information literacy for her photography students. She projects an image of CREATE on the screen, describing each element as a way to introduce the purpose of the library instruction, and specifically using Conversation, Revision, and Exploration as themes during the sessions. After a series of two library periods, she also asked students to reflect on and write down their understanding of each concept.

For Conversation, one student wrote "Looking up artists gives one the ability to converse about the subjects one is interested in, [and] also allows the artist to enter into a conversation with other artists." To describe Exploration, another student wrote, "Research opens other avenues[;] keywords send one on different tangents." These comments seem to indicate a student awareness of the impact of research to inform their work.

\section{The challenges}

While the librarians have found CREATE to be adaptable to many different settings and purposes, there have been some challenges unique to each working environment. For example, Meeks recently transitioned from being the sole instruction librarian at a small art school to working at a large state institution as a liaison to several departments including Visual Art. She has found it challenging to focus on visual art; however, it has highlighted the unique research prac- 
tices of other creative disciplines-such as English and Film and Media-that can be linked to creativity and knowledge creation. Although CREATE was developed with visual artists and designers in mind, it has helped inform instruction in other disciplines. Also, carefully contextualizing the Framework for one discipline is very time-consuming work. The time constraint of serving as a liaison to many departments may be a barrier to further developing such devices for disciplines not tied to the creative practice.

Because Garcia does not have a Fine Arts background, working through and articulating the CREATE concepts that are more specific to artistic practice (particularly Thoughtful and Experiential) proved challenging. However, it did start a conversation with the faculty member and provided an opportunity for more meaningful coteaching during the library session. Because CREATE values intuition and experience, as well as research, in the classroom, Garcia underscored the connection between research and artistic practice and the instructor addressed the role of personal experience in the creative process. Together, they highlighted the use of research to contextualize the work more broadly, beyond one's own viewpoint.

At her institution, Vincent has received some negative feedback from course instructors concerned about introducing theoretical concepts instead of demonstrating "practical" research skills for students. This divergence reveals a divide between the goals of the library instruction and faculty perceptions of what library instruction is. However, it also encourages more consideration about how to communicate and advocate for what librarians teach, since practical skills and an intellectual framework for information literacy are mutually supportive.

Peterson uses CREATE as a behind-thescenes tool and does not explicitly discuss it with students or faculty. Similar to Vincent, the challenge for her comes when developing a lesson plan that considers the larger information literacy concepts that inform the more skills-based content some instructors want emphasized. Instead of only teaching fleeting skills (i.e., knowing how to navigate an institution's discovery tool), CREATE challenges art librarians to keep the focus on the conceptual underpinnings of information literacy.

\section{The future}

CREATE has broad applicability when planning and implementing a wide array of information literacy activities. When the concepts are incorporated into teaching practice, art librarians can help students understand that research is what artists do (and often what student-artists have been doing without realizing it) in order to tell a more complete story about their creative process and the resulting work. Additionally, CREATE is useful for outreach, illustrating for faculty, administrators, and other stakeholders the value of information literacy in artistic practice. Finally, because it adapts the Framework to a particular discipline, the authors hope CREATE will start a conversation with liaison librarians in other subject areas about the Framework's potential for improving information literacy education throughout the profession.

\section{Note}

1. James Elmborg, "Critical Information Literacy: Implications for Instructional Practice," Journal of Academic Librarianship 32, no. 2 (2006): 192. $\not 2$

\section{ACRL Framework for Information Literacy Toolkit}

The ACRL Framework for Information Literacy Toolkit is a freely available professional development resource that can be used and adapted by both individuals and groups in order to foster understanding and use of the ACRL Framework for Information Literacy for Higher Education. The toolkit is available on the ACRL LibGuides site at http://acrl.libguides.com /framework/toolkit. 